\title{
Open-Ended Versus Multiple-Choice Response Fomats-lt Does Make a Difference tor Diagnostic Purposes
}

\author{
ำ \\ Tำ

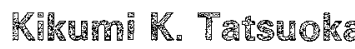 \\ บทำำำ
}

The purpose of the present study was to examine the effect of response format-open-ended (OE) versus multiple-choice (MC)-on the diagnosis of examinee misconceptions in a procedural task. A test in fraction addition arithmetic was administered to 285 eighthgrade students, 148 of whom responded to the oE version of the test and 137 to the MC version. The two datasets were compared with respect to the underlying structure of the test, the number of different error types, ard the diagnosed sources of misconception (bugs) reflected in the response paterns. The overall results indicated considerable differences between the wwo formats, with more favorable results for the OE format.

The effect of item format on exarninee responses has been studied extensively in the past decade. The equivalence of open-ended (OE) items (also known as free-response or recall items) and multiple-choice (MC) items (also known as recognition items) has been addressed by psychometricians and cognicive psychologists. From an information-processing point of view, different models for the two response formats have been suggested (e.g., Bender, 1980). The commonly held view suggests that recall items require examinees to both search for and retrieve information, whereas recognition items require them only to discriminate among the presented information.

APPLIED PSYCHOLOGICAL MEASUREMENT

Vol. 11, No.4, December 1987, pp. 385-395

(c) Copyright 1987 Applied Psychological Measurement Inc. 0146-6216/87/040385-11\$1.80
Comparisons between the two formats have used various criteria, such as success rate (e.g., Estes \& DaPolito, 1967; Heim \& Watts, 1967; Lofus \& Loftus, 1976; White \& Carcelli, 1982), item difficulty (e.g., Cook, 1955; Merwin \& Womer, 1969), the traits measured by the test (e.g., Traub \& Fisher, 1977; Ward, 1982; Ward, Frederiksen, \& Carlson, 1980 ), retention rate (e.g., Duchastel \& Nungester, 1982; $\mathbb{K}$ umar, Rabinsky, \& Pandey, 1979), and examinees' strategies for preparing for the test (e.g., Freund, Brelsiford, \& Atkinson, 1969; Kumar et al., 1979; Loftus, 1971; Tversky, 1973). The results of these studies, however, seem quite inconclusive. A few indicate an advantage for the openended format, while others show no difference between the two formats.

Most of these studies used tests of reading comprehension or vocabulary, domains in which the cognitive mechanisms underlying recall versus recognition are applicable. One question that arises, however, is whether the same distinction holds for $M C$ and $O E$ items in procedural tasks such as arithmetic operations. Moreover, none of the studies compared $O E$ to MC items with respect to information from incorrect responses.

Current research into the diagnosis of examinee misconceptions has focused on procedural tasks (see Birenbaum \& Shaw, 1985; Birenbaum \& Tatsuoka, 1982, 1983; Brown \& Burton, 1978; Burton, 1981; Marshall, 1980; Matz, 1980; Tatsuoka, 1983, 1985, 1986a; Van Lehn, 1981). A recommended procedure for designing a MC test is to 
consider examinee responses to an oE test, and then construct distractors based on the frequencies of the incorrect responses to the OE test. However, the equivalence of the two formats for diagnostic purposes has not yet been examined. This issue is addressed by the present study, which evaluated the effect of the response format (MC Vs. OE) on the rules of operation underlying examinees' response pattems in fraction-addition arithmetic items.

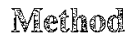

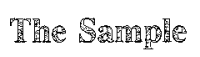

The sample consisted of 285 eighth-grade students from a junior high school in a Midwestem town in the U.S. All students completed the classroom instruction on fraction addition prior to taking the test. An OE test in fraction addition was administered to 148 students. The remaining $137 \mathrm{su}$ dents were administered the $M C$ version of the test. Both groups consisted of students attending the mathematical laboratory at the school in two corrsecutive years. (The two samples are representative of the eighth-grade population in that school because they consist of students with various degrees of competence in mathematics. Scheduing conHicts, interest in using computer-aided instruction, or poor mathematical performance are the main reasons for attending the laboratory classes.)

\section{The "Test}

The oE version of the test consisted of 38 items with 2 parallel sets of 19 items each. The MC version consisted of the same items as the OE version with 5 distractors each. The distractors were constructed on the basis of a frequency count of errors committed by students on the $O E$ version in a pilot study. Both versions of the test were administered in paper-and-pencil form, with items in the same order. The test design was based on an extensive task analysis of fraction addition operations. The items were selected to represent typical errors identified in previous studies (Tatsuoka, 1984a). (For more details on the test design, see Birenbaum \&
Shaw, 1985; Klein, Birenbaum, Standiford, \& Tatsuoka, 1981.)

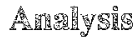

Three types of analyses were used in order to examine the effect of the response format. The first focused on the underlying structure of the two test forms. Using correctincorrect item scores, Guttman-Lingoes smallest space analysis (SSA-I; Lingoes, 1972) was employed. This nommerric multidimensional scaling procedure maps the items into points in Euclidean space. Conrelations are employed as measures of proxinity berween the items, in order to determine the corresponding interpoint distances. The level of measurement is ordinal; therefore, a monotone rasusformation is applied to the correlations in order to maximize the goodness of fit of the solution to the data (as messired by the coefficient of alienation) in a minimal sumber of dimensions. The solutions are usinally very parsimonious, and an adequate solution is frequently obtained in two or three dimensions for quice complex sets of data (Schlesinger \& Guttman, 1969). The interpretation of the results depends upon the configuration of the points.

The second analysis compared the two response formats with respect to the types of errors conminted by the students. The computer mrogran SPBUG (Baillie \& Tatswoka, 1983) was used to generak responses to each item. The items were first expressed by an algebraic relation of 6 variables, (a $b / c+d$ elf), where $a$ and $d$ represent whole numbers and $b / c$ and elf are fractions; then, based on a logical error analysis (Klein et al., 1981), dîferent possible combinations of erroneous algebraic denivations were programmed. SPBUG then diagnosed the sonrces of error by matching siudents' responses with the responses generated by the program.

A previous anallysis of the $O E$ version of the test, using SPBUG, idencified 70 different error types, which accourited for $80 \%$ of the free responses (Tatswoka, 1984a). Because the MC test included only 20 different error types, the oz responses were coded twice, once according to all the idtentiliable

Downloaded from the Digital Conservancy at the University of Minnesota, http://purl.umn.edu/93227. May be reproduced with no cost by students and faculty for academic use. Non-academic reproduction requires payment of royalties through the Copyright Clearance Center, http://www.copyright.com/ 
error types and once according to those represented in the MC test. Thus, two datasets for oz responses were created. The finst dataset will be referted to hernceforti as of, whereas the second will be referred to as or/hC (i.e., the of datase coded according to the distractors of the BC test). The or and oE/MC datasets were compared to the $\mathrm{MC}$ dataset with respect to the mean number of different error oypes.

The thing anatysis focused on the entire response pattern in atr atternpt to diagnose the sivdents' sources of misconception ("bugs") with respect to fraction addition operations. (As used here, bug denotes a response patern hat includes a set of emor types which resut from ill-composed rules of operation. For cxamples of bugs in fraction operations see Pirenbaurn ge Shan, 1985; Tatsuoka, 1984a, 1986a.) The "rule space" method developed by Tatsuoka (Taisuoka. 1983, 1984b, 1985) was cmployed for this andysis.

The role space is a method hat classifies response pattems into probability ellipses representing emoneous retes of operation, or bugs (Tatsuoka 星 Tarsuoka, 1987). All the response patterns resulfing from both the correct and the erroneous rules are mapped into a two-dimensional space, where one dimension represents the level of the latent ability being measured by the test $(0 \mathrm{im} \mathbb{R} \mathrm{R}$ tems), and the other is an index of the arypicality of the response pattern (6; Trusuoka, 1984b). These wo parameters were calculated for the dataset at hand, using the two parameter logistic model. The values of $\theta$ and $\$$ for a simulated response patem for each bag, selected from a "bug library," are mapped into this space creating the center of cach probability ollipse. The actual response paterns are then classified into these ellipses. (See Tatsuoka \& Tatsuoka, 1987, for details about the classificarion procedure.)

The bug library employed in the current study was constructed using wo contrasting methods. One method was based on combinations of differenu item types: addition of simple fractions or mixed qumbers with like or molike denominators. The resulting 16 item-type combinations were used to generate the bugs. An item was assigned a value of 1 if it belonged to a certain item type, and a value of otherwise. It should be noted that a few of the response pattems generated by this method are less likely to occur, due to differences in the number of procedural steps involved in solving the various irem types.

The other method for generating bogs was based on a rational task analysis (Klein ot al., 1981; TatSiroka, 1986b; Tatsuoka \& Chevalaz, 1984). Task components (atuibutes) underlying every item were determined, and bugs were generated by assigning a value of 1 to all items sharing the same atribute or combination of attributes which were the target for the dimgnosis, and assigning a value of 0 to the remaining items. As a result, a total of 35 ellipses were used for classifying sudents' response pattems. (See Tausuoka, 1986a, for detailed information abour the bugs.)

Due to the generating procedure of the first method, a few ellipses were difficult to interpret (e.g., a category of response patems with conrect answers to mixed numbers with unitke denominators, and incorrect answers for the remaining items). Consequently, the 35 ellipses were classified into two categories: those which are easy to rationalize and those that are difficult to rationalize. The oE and MC datasets were compared with nespect to these two categories using a $\alpha^{2}$ significance test. Finally, the shortest Mahalanobis generalized distance $\left(D^{2}\right)$ Getween the point contesponding to the studerit response patem in the rule space and the centroid of the bug probability ellipse (Tatsuoka 惩 Taisuoka, 1987) was computed for each siudent. The $D^{2}$ means for the of and the ic groups wrere compared, as were the $\theta$ and $\zeta$ parameters, using thtests. Programs from SPSS (Nie, Hull, Jenkins, Steinbrenner, Brent, 1975) were used for the statistical analyses.

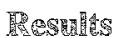

The underlying structure of the test in the oE and MC datasets was examined uring smallest space analysis. The rwo-dimensional solution seemed adequate for both datasets, yielding coefficients of

Downloaded from the Digital Conservancy at the University of Minnesota, http://purl.umn.edu/93227. May be reproduced with no cost by students and faculty for academic use. Non-academic reproduction requires payment of royalties through the Copyright Clearance Center, http://www.copyright.com/ 


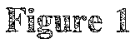

Two-Dimensional Results From Smallest Space Analysis (Ttems With Like Denominators Are Circled)

(a) OE Fraction Addition Test $(N=148)$

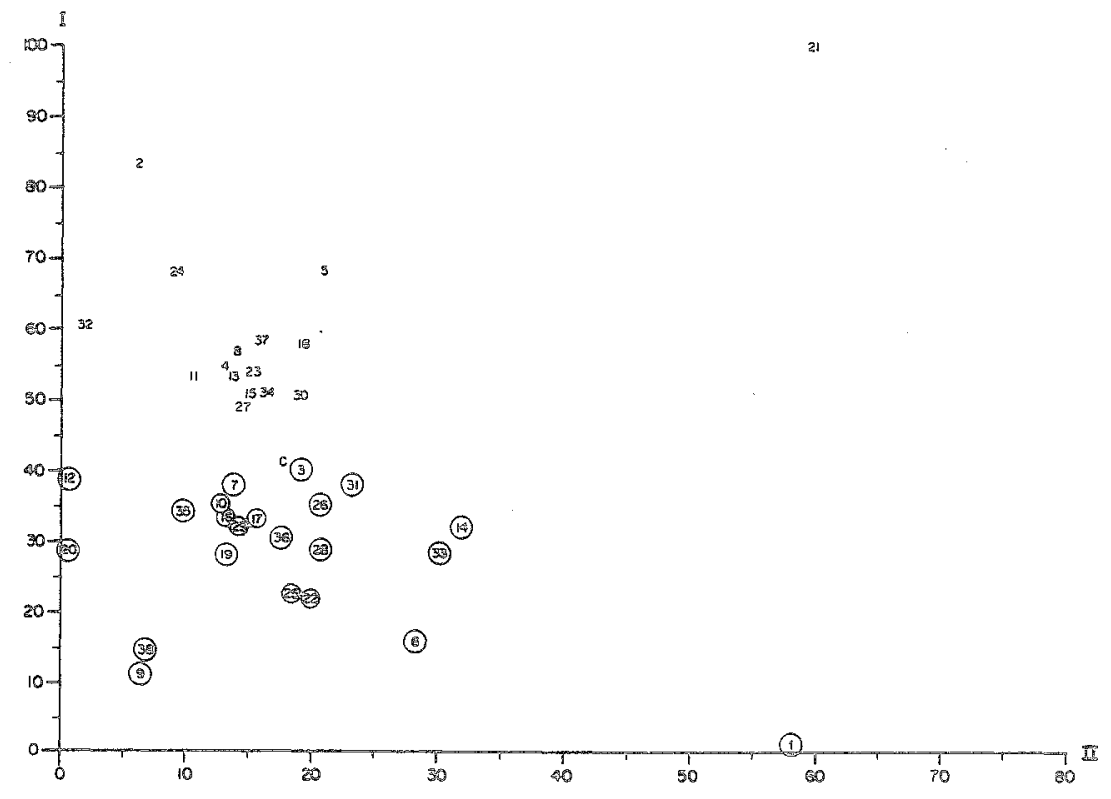

(b) MC Fraction Addition Test $(N=137)$

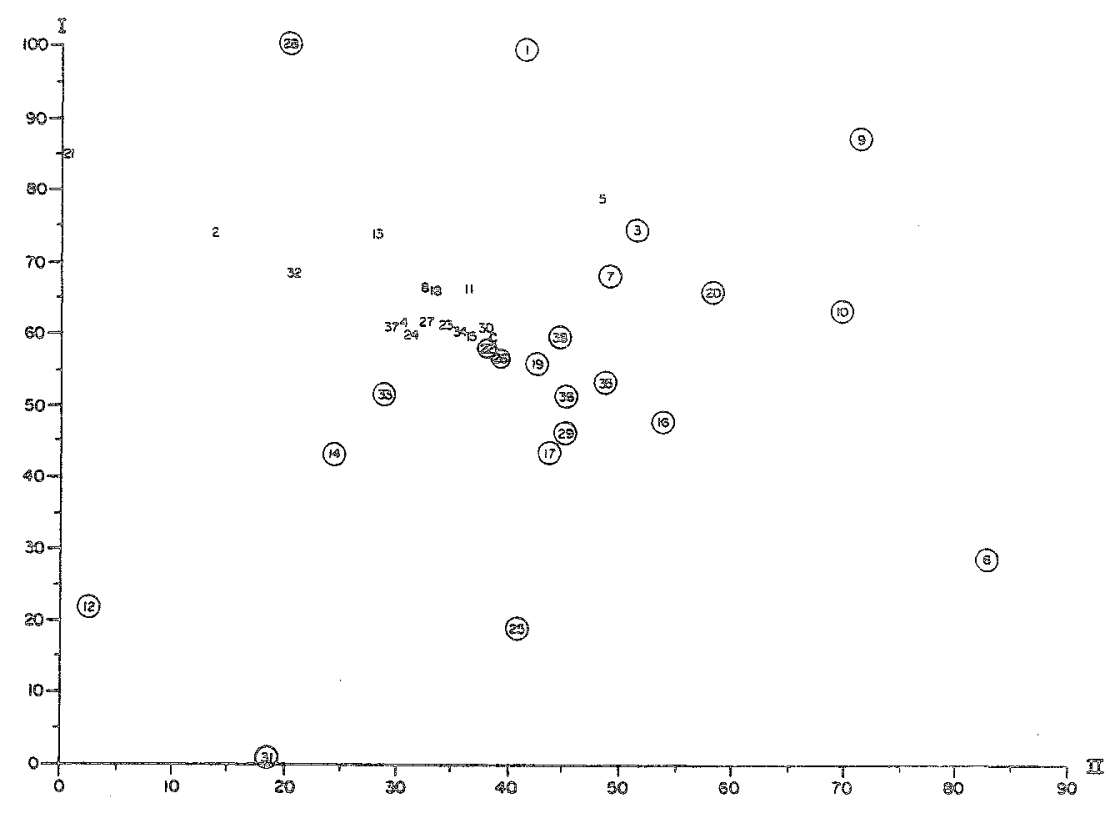

Downloaded from the Digital Conservancy at the University of Minnesota, http://purl.umn.edu/93227. May be reproduced with no cost by students and faculty for academic use. Non-academic reproduction requires payment of royalties through the Copyright Clearance Center, http://www.copyright.com/ 
allenation of .0021 and .0025 for the OE and the MC datasers, respectively. As cam be seen in Fignre 12, the OE dataset yielded two distinct clusters of items, the upper one consisting of items with unlike denominators and the lower one consisting of items with like denominators. However, examination of Figure $1 \mathrm{~b}$, which represents the $\mathrm{MC}$ dataset, shows a more diffused scater of points in the twom dimensional space wrih no clear distinction between different tyoes of items.

Table 1 presents the interconelation matrices for the two datasets. A factor-analytic examination of those matrices, using the principal factor method, yielded two clear factors in the oE dataset where all items with like denominators loaded on one factor and all items with unlike denominators loaded on the second factor. The factor solution for the MC dataset yielded a less clear distinction; 12 of the items failed to load as expected.

The two datasers were compared with respect to basic test charactenistics, including reliability coefficients, total scores, number of omitted items, and number of identified efror types. Those results are summarized in Talle 2. The $\alpha$ reliability coefcients (Cronbach, 1951) for the wo test foms were high (.98 for the OE rest and .97 for the MC test), indicating that items within each tese form are homogeneous. As can be seen in Table 2, the rotal test score means for $O E$ and $\mathrm{MC}$ did not differ sigrificantly. (Neither did the means of the $\theta$ estimates, as will be shown later.) No significant difference was detected between the mean numbers of onitted items in the OE and $\mathrm{MC}$ datasets.

The number of identified error types was sigmificantly lower in the 1 WO OE datasets (OE and OE/ MC) than in the MC dotaset. The OE/MC dataset yielded a significantly lower mean than the OE dataser. These results are presented in Table 3 . It shond be noted that some of the enrors in the $\mathrm{OE}$ dataset remained unidentifiable by SPBUG. (Tatsuoka, 1984a, reported that the SPBUG identification rate for the OE rest Was $80 \%$ of the incorrect responses.) The OE/MC dataset yielded an even lower identification rate because not all the errors that were identified in the oE dataset were incorporated in the distractors of the MC test.
This difference in enor identifaction rate was taken into consideration when the numbers of different error types in the three datasets were compared. As can be seen in Table 3, even after adjusting the wo datasets to compensate for the difference in error identification rate, they yielded significantly lower means than the MC for the number of different error cypes. A statistically significant difference was also detected between the two OE darasets with respect to this variable, with the OE/MC yielding the lower mean.

These results are on the conservative side because the MC dataset included only 21 response types ( 20 for incorrect responses and 1 for the correct response), whereas the oE dataset included 70 response types (69 for incorrect responses and 1 for the correct response). If this ratio had been considered, the mean number of error types in the MC dataset would have increased to 22.4. (This calcalation akes into consideration that 70 error types were found in a dataset where the identiticarion rate was $80 \%$.) The means to be compared following this adjustment would then be 22.4 for $\mathrm{MC}, 3.6$ for $\mathrm{OE}$, and 1.8 for $\mathrm{OE} / \mathrm{MC}$. Obviously, the differences between these means give a much more dramatic appearance to the results.

The third type of analysis examined the differences between the $\mathrm{OE}$ and the $\mathrm{MC}$ datasets from another perspective. Using the rulle space rechnique, bug ellipses were constructed and classified into two categories of "rationally interpretable" and "Taúionally uninteroretable" bugs. Table 4 presents the cross-tabulation between these two categories and the two test fomats (OE and MC). As can be seen in the table, $84.5 \%$ of the response patterns in the oE dataset were classified into the category of rationally interpretable bugs, as com pared to only $63.5 \%$ of the response pattems in the MC dataset. These differences were significant, as can be seen by the values of the $x^{2}$ statistics.

A further analysis compared the response patterms of the two groups with respect to the two coordinates of the rule space, the ability parameter $\theta$ and the atypicality-of-response index 6 , as well as to the shortest Mahalanobis generalized distance $\left(D^{2}\right)$ from the centroid of the bug-ellipse to a given 
Table 2

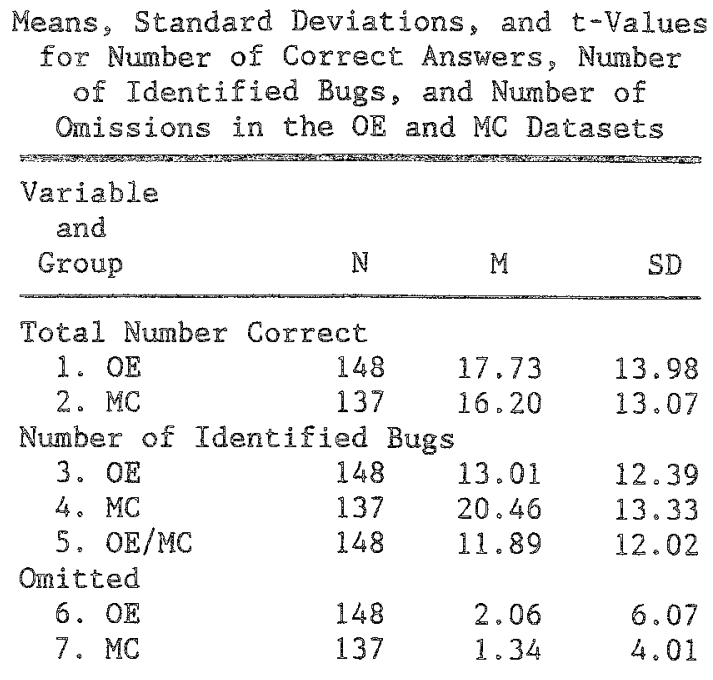

t-values: independent samples

(1) $\&(2) t=-.95 \mathrm{t}(283 \mathrm{df})$

(4) \& (5) $t=5.71$ (283 df $)$

(3) $\delta(4) t=4.89^{\text {\%et }}(283 \mathrm{df})$

(6) \& (7) $t=-1.18 \quad(283 \mathrm{df})$

t-values: dependent samples

(3) $\&(5) t=1.29 \quad(147 \mathrm{df})$ $\mathrm{p}<.01$

point corresponding to a student response pattern. As can be seen in Table 5, the differences between the $\mathrm{OE}$ and the $\mathrm{MC}$ datasets with respect to $\theta$ and $\zeta$ were insignificant, whereas $D^{2}$ yielded a significantly higher value in the MC dataset than in the OE dataset.

These results indicate that the OE group, although not differing significantly from the $\mathrm{MC}$ group with respect to ability to solve fraction addition problems, can be better diagnosed with respect to bugs or sources of misconception underlying the response pattems. In order to illustrate the differences in the classification fit between the oE and the MC groups, a few ellipses were chosen and the two groups were plotted against them. Figures $2 a$ and $2 b$ present these results. As can be seen in the figures, the $\mathrm{OE}$ dataset captured more of the specified ellipses than did the $\mathrm{MC}$ dataset.

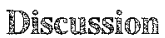

The results of this sudy indicated considerable differences between the two formats, with more favorable results for the of format. The underlying struchure, as examined by smallest space analysis, seemed clearer in the or dataset, where the configuration of the items in the two-dimensional space clearly indicated wo clusters: one of items with like denominarors and the other of items with unlike denominators. The item configuration for the MC dataset, on the other hand, seemed quite diffuse, with no distinct separation beween the different item types.

The results of the error analysis provided an even clearer distinction between the rwo response formats. Although the wo groups did not differ in the ability to solve fraction addition problems, the MC dataset included a significantly larger number of different error types than the OE dataset. This resulted in a less appropriate overall classification rate in the rule space. These results seem to indicate that students who have not mastered the task tend

Table 3

Means, Standard Deviations, and t-Values for Number of Different Error Codes in Each Dataset

\begin{tabular}{|c|c|c|c|}
\hline Group & $\mathbb{1}$ & $M$ & SD \\
\hline 1. $\mathrm{OE}$ & 148 & 2.93 & 2.12 \\
\hline 2. $M C$ & 137 & 5.62 & 3.17 \\
\hline 3. $\mathrm{OE} / \mathrm{MC}$ & 148 & 1.80 & 1.50 \\
\hline 4. OE adjusted ${ }^{3}$ & 148 & 3.67 & 2.65 \\
\hline 5. OE/MC adjusted ${ }^{2}$ & 148 & 2.26 & 1.88 \\
\hline
\end{tabular}

adjusted by adding $1 / 4$ to number of rules (to adjust for $80 \%$ bug identification rate in open-ended data). t-values: independent samples

(1) $\&(2) t=8.36^{\text {*nt }}(235 \mathrm{df}$ )

(3) $\&(2) t=-12.84^{*} \quad$ (191 df $)$

(5) \& (2) $t=-10.81^{\text {sos }} \quad(283 \mathrm{dit})$

(4) \& (2) $t=-5.67^{2} \quad(283 \mathrm{~d} f)$

t-values: dependent samples

(1) $\&(3) t=-10.28^{2 *} \quad(147 \mathrm{df})$ $\mathrm{p}<.001$

Downloaded from the Digital Conservancy at the University of Minnesota, http://purl.umn.edu/93227. May be reproduced with no cost by students and faculty for academic use. Non-academic reproduction requires payment of royalties through the Copyright Clearance Center, http://www.copyright.com/ 
Table 4

Frequencies (N) and Percentages (\%) of Test Format by Bug Categories

\begin{tabular}{|c|c|c|c|}
\hline \multirow{2}{*}{$\begin{array}{l}\text { Test } \\
\text { Format }\end{array}$} & \multicolumn{3}{|c|}{ Bug Category } \\
\hline & Uninterpretable & Interpretable & Tota1 \\
\hline \multicolumn{4}{|l|}{$O E$} \\
\hline $\mathrm{N}$ & 23 & 125 & 148 \\
\hline$\%$ & 15.5 & 84.5 & 51.9 \\
\hline \multicolumn{4}{|l|}{$\mathrm{MC}$} \\
\hline N & 50 & 87 & 137 \\
\hline$\%$ & 36.5 & 63.5 & 48.1 \\
\hline \multicolumn{4}{|l|}{ Tota1 } \\
\hline $\mathbb{N}$ & 73 & 212 & 285 \\
\hline$\%$ & 25.6 & $24 \cdot 4$ & 100.0 \\
\hline
\end{tabular}

to be less consistent in applying their rules of operation for solving procedural tasks when faced with a MC format than with an OE one.

It seems that the cognitive process involved in these two response formats (in a procedural task) is quite different. According to Fisher and Lipson (1985), "Hlumans exhibit a fairly strong tendency to avoid extra mental effort, so as to minimize their information processing load' (p.65). Although in the OE items students had to compute the answer "from scratch," in the MC test they could retrieve cues from the distractors, thus shorteming the process, perhaps with more effort directed toward judging the "correctness" of the answer given in the distractors than toward carying out the entire "tedious" calculation. However, because the distractors in the MC test were carefully chosen to represent common exrors rather than random incorrect answers, the task of selecting the correct answer became more complicated and resulted in a wider variety of emor types, a greater portion of which were rationally uninterpretable.

The implications for diagnostic achievement resting in procedural tasks are obvious. MC tests, though considerably easier to score, may not pro vide the appropriate information for identifying stu-

Table 5

Means, Standard Deviations, and t-Values for $\theta, \zeta$, and for the Mahalanobis Generalized Distances

$\left(D^{2}\right)$ From the Centroids in the Rule Space for the $O F$ and the $M C$ Datasets

\begin{tabular}{cccccccc} 
Variable & Group & N & M & SD & df & $t$ & $p$ \\
\hline$\theta$ & OE & 148 & -.28 & 1.31 & 283 & -.69 & $>.05$ \\
$\zeta$ & $M C$ & 137 & -.18 & 1.15 & & & \\
\multirow{5}{*}{$D^{2}$} & OE & 148 & .18 & 1.18 & 258 & 1.07 & $>.05$ \\
& MC & 137 & .01 & 1.50 & & & \\
& OE & 148 & .38 & .51 & 245 & -2.17 & $<.05$ \\
& $M C$ & 137 & .54 & .71 & & & \\
\hline
\end{tabular}

Downloaded from the Digital Conservancy at the University of Minnesota, http://purl.umn.edu/93227. May be reproduced with no cost by students and faculty for academic use. Non-academic reproduction requires payment of royalties through the Copyright Clearance Center, http://www.copyright.com/ 
Fingugre 2

Rule Space Plots

(a) OE Dataset

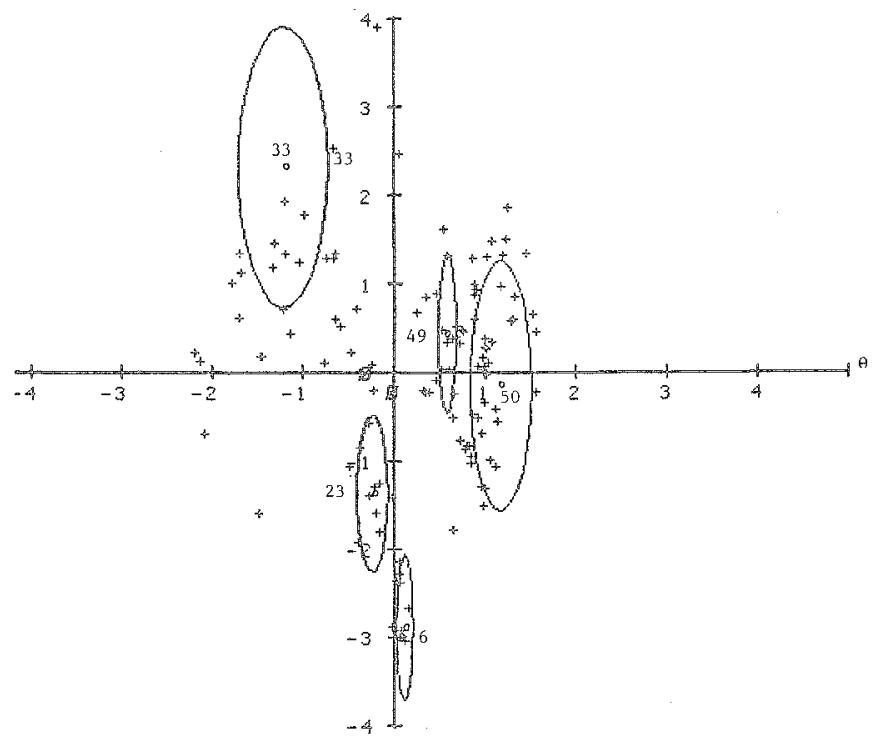

(b) MC Dataset

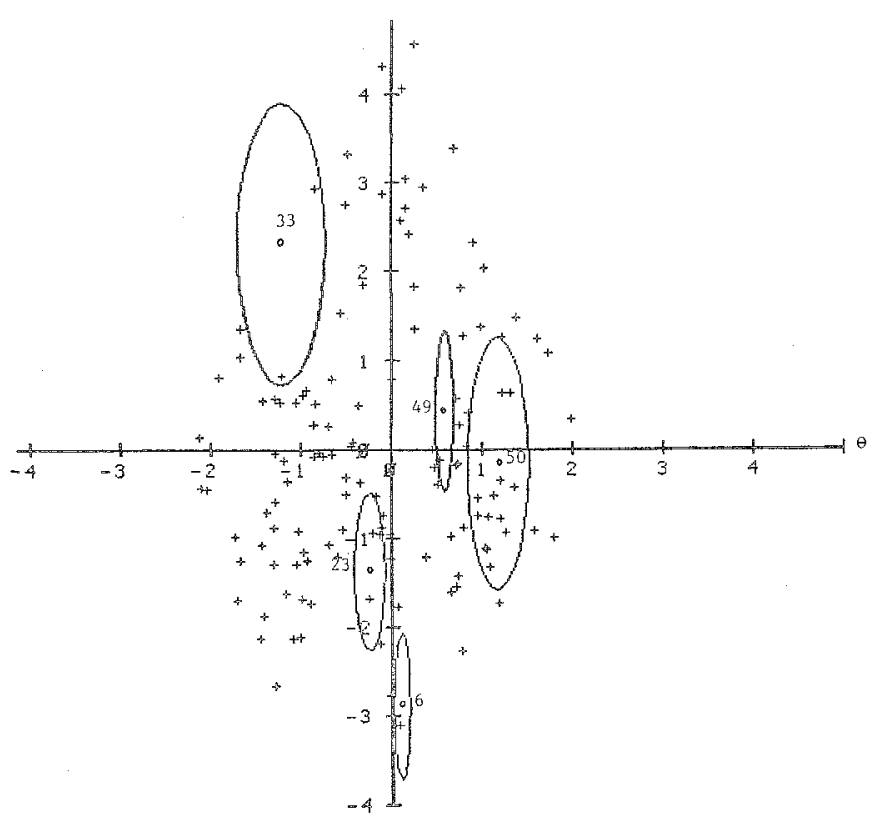

Downloaded from the Digital Conservancy at the University of Minnesota, http://purl.umn.edu/93227. May be reproduced with no cost by students and faculty for academic use. Non-academic reproduction requires payment of royalties through the Copyright Clearance Center, http://www.copyright.com/ 
dents' misconceptions with respect to the given subject matter. The oE format seems more appropriate for this purpose.

\section{Referemes}

Baillie, R., \& Tatswoka, 洫. K. (1983). SPBUG: A computer program for diagnosing bugs and analyzing responses. Urbana $\mathrm{IL}$ : University of Illinois, ComputerBased Education Research Laboratory.

Bender, T. A. (1980, April). Processing multiple choice and recall test questions. Paper presented at the annual meeting of the American Educational Research Association, Boston. (ERIC ED189160)

Birenbaum, M., \& Shaw, D. J. (1985). Task specification chart-a key to a better understanding of test results. Joumal of Educational Measurement, 22, 219 230.

Birenbaum, M., \& Tatsuoka, K. K. (1982). On the dimensionality of achievernent test data. Jourral of Educational Measurement, 19, 259-266.

Birenbaum, M., \& Tatsuoka, K. K. (1983). The effect of scoring based on algorithms underlying the students' response patterns on the dimensionality of achievement rest data of the problem solving type. Joumal of Educational Measurement, 20, 17-26.

Brown, J. S., \& Burton, R. R. (1978). Diagnostic models for procedural bugs in basic mathematical skills. Cognitive Science, 2, 155-192.

Burton, R. R. (1981). Diagnostic bugs in a simple procedural skill. Palo Alto CA: Xerox Palo Alto Research Center.

Cook, D. L. (1955). An investigation of three aspects of free response and choice type tests at the college level. Dissertation Abstracts International, 15, 1351 (University Microfilms No. A55-1791).

Cronbach, L. J. (1951). Coefficient alpha and the internal structure of rests. Psychometrika, 16, 297-334.

Duchastel, $\mathbb{P}$. C., \& Nungester, R. (1982). Testing effects measured with alternate forms. Journal of $E d$ mational Research, 75, 309-314.

Estes, W. K., \& DaPolito, F. J. (1967). Independent variation of information storage and retrieval processes in paired-associate learning. Journal of Experimental Psychology, 75, 18-26.

Fisher, 仿. M., \& Lipson, J. H. (1985). Information processing interpretation of errors in college science leaning. Instructional Science, 14, 49-74.

Freund, R. D., Brelsford, J. W., Jr., \& Atkinson, R. C. (1969). Recognition vs. recall: Storage or retrieval differences? Quarterly Journal of Experimental Psychology, 21, 214-224.

Heim, A. W., \& Watts, K. P. (1967). An experiment on multiple-choice versus open-ended answering in a vocabulary test. British Joumal of Educational Psy chology, 37, 339-346.

Klein, M., Birenbaum, M., Standiford, S. N., \& Tatsuoka, $\mathrm{K}$. K. (1981). On the construction of an erpordiagnosing tesi in fraction arithretic (Technical Report 81-6-NIE). Urbana $\mathbb{L L}$ : University of $\mathbb{I l l i n o i s , ~}$ Computer-Based Education Research Laboratory.

Kumar, V. K., Rabinsky, L., \& Pandey, T. N. (1979), Test mode, test instructions, and retention. Contemporary Educational Psychology, 4, 211-218.

Lingoes, J. C. (1972). The Guteman Lingoes nommetric program series. Ann Arbor MI: Matesis Press.

Loftus, G. R. (1971). Comparison of recognition and recall in a continuous memory task. Jormal of Experimental Psychology, 91, 220-226.

Loftus, G. R., Loftus, E. G. (1976). Human memory. The processing of information. Hillsdale NI: Erbaum.

Marshall, S.P. (1980). Procedural networks and production systems in adaptive diagnosis. Instructional Science, 9, 129-143.

Matz, M. (1980). Towards a computational theory of algebraic competence. Journal of Mathematical $\mathbb{R}_{2}$ havior, 3, 93-166.

Merwin, J. C., \& Womer, F. B. (1969). Evaluation in assessing the progress of education to provide bases of public understanding and public policy. In $\mathbb{R}$. W. Tyler (Ed.), Educational evaluation: New roles, new means-The sixty-eighth yearbook of the National Society for the Study of Education (Part II, po. 305334). Chicago: University of Chicago Press.

Nie, N. H., Hull, C. H., Jenkins, J. C., Steinbrenner, K. S., \& Brent, D. H. (1975). Statistical package for the social sciences (SPSS). New York: McGraw-Hill.

Schlesinger, I. M., \& Guttman, L. (1969). Smallest space analysis of intelligence and achievement rests. Psychological Bulletin, 71, 95-100.

Tatsuoka, K. K. (1983). Rule space: $\mathbb{A}$ approach for dealing with misconceptions based on ifen response theory. Joumal of Educational Measurement, 20, 345354.

Tatsuoka, K. K. (Ed.) (1984a). Analysis of errors in fraction addicion and sthbraction problems (Final Report for Grant No. NHE-G-81-0002). Urbana H: University of Illinois, Computer-Based Education Research Laboratory.

Tatsuoka, K. K. (1984b). Caution indices based on item response theory. Psychometrika, 49,95-110.

Tatsuoka, K. K. (1985). A probabilistic model for diagnosing misconceptions by the pattern classification approach. Journal of Educational Statistics, 10,5573.

Tatsuoka, K. K. (1986a). Diagnosing cognicive errors: Statistical pattem classification based on item response theory. Behaviormetrika, 19,73-86.

Tatsuoka, $\mathbb{K}$. K. (1986b, July). Toward an integration of item response theory and cognitive diagnosis. Paper 
presented at the ONR Conference on Diagnostic Monitoring of Skill and Knowledge Acquisition, Princeton NH.

Tatsuoka, K. K., \& Chevalaz, M.C. (1984). A map representation of misconceptions in the rule space: Fraction addition arithmetic (Research Report 84-2NIE). Urbana LL: University of Illinois, ComputerBased Education Research Laboratory.

Tatsuoka, K. K., \& Tatsuoka, M. M. (1987). Bug distribution and statistical pattern classification. PSychometrika, 52, 193-206.

Trab, $\mathbb{R} . \mathbb{E}$. \& Fisher, C. $\mathbb{W}$. (1977). On the equivalence of constructed-response and multiple-choice tests. Applied Psychological Measurement, 1, 355-369.

Tversky, $\mathbb{B}$. (1973). Encoding processes in recognition and recall. Cognitive Psychology, 5, 275-287.

Van Lehn, K. (1981). Rugs are not enough: Empirical suddies of bugs, impasses and repairs in procedural skills (Technical Report CIS-11). Palo Alto CA: Kerox, Palo Alto Research Center.

Ward, W. C. (1982). A comparison of free-response and mulliple-choice forms of verbal aptitude tests. Applied Psychological Measurement, $6, \mathbb{1}-11$.

Ward, W. C. Frederiksen, N., \& Carlson, S. B. (1980). Construct validity of free response and machine-scorable forms of a test. Journal of Educational Measusement, 17, 11-29.

White, K. K., \& Carcelli, L. (1982, March). The effect of iten format on sudents' standardized mathematics achievement test scores. Paper presented at the annual meeting of the American Educational Research Association, New York. (ERIC ED219425)

\section{Acicing}

This research was partially sponsored by the Personnel and Training Research Program, Psychological Sciences Division, Office of Naval Research, whder Contract No. No0014-82-K-0604, NR 150-495. This research was also partially supported by the National Institute of Educaiton, under Grant No. NHE-G-81-0002. The opinions expressed herein do not necessarily reflect the position or policy of the National Insitutu of Education and no official endorsement by the National Institute of Education should be inferred. Several of the analyses presented in this report were performed on the PLATO ${ }^{(19}$ stem. The PLATO system is a development of the University of Illinois and PLATO is a service mark of Control Data Corporation.

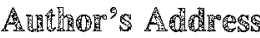

Send requests for reprints or further information to Menucha Birenbaum, School of Education, Tel-Aviv University, Ramat-Aviv, Tel-Aviv 69978, Israel. 